Tableau $n^{\circ}$ 1: Relation between comorbidities and the disease activity parameters of rheumatoid arthritis and Spondyloarthritis

\begin{tabular}{lccc}
\hline & DAS 28 ESR & BASDAI & ASDAS CRP \\
\hline Diabetes & $\mathrm{p}=0.737$ & $\mathrm{p}=0.633$ & $\mathrm{p}=0.652$ \\
High Blood pressure & $\mathrm{p}=0.252$ & $\mathrm{p}=0.998$ & $\mathrm{p}=0.323$ \\
Obesity & $\mathrm{p}=0.565$ & $\mathrm{p}=0.585$ & $\mathrm{p}=0.904$ \\
Dyslipidemia & $\mathrm{p}=0.332$ & $\mathrm{p}=0.349$ & $\mathrm{p}=0.997$ \\
Osteoporosis & $\mathrm{p}=0.372$ & $\mathrm{p}=0.989$ & $\mathrm{p}=0.020$ \\
Gastrointestinal ulcer & $\mathrm{p}=0.829$ & $\mathrm{p}=0.286$ & $\mathrm{p}=0.910$
\end{tabular}

DAS: disease activity score; BASDAI: Bath Ankylosing Spondylitis Disease Activity Index; ASDAS: Ankylosing Spondylitis Disease Activity Score

Conclusion: According to this study, in patients with RA and SpA associated comorbidities may occur more frequently than expected (54\%). However, they had no relation to the activity of the disease according to their frequencies or their types, except osteoporosis which was significantly associated with the SpA activity. Identifying these comorbidities may affect the management and treatment decisions for these patients to ensure an optimal clinical outcome.

Acknowledgments: none

Disclosure of Interests: None declared

DOI: 10.1136/annrheumdis-2020-eular.3738

\section{AB0263 SEXUAL FUNCTION IN WOMEN WITH RHEUMATOID ARTHRITIS: A CASE-CONTROL STUDY.}

G. Serna-Peña ${ }^{1}$, S. M. Sánchez Romo ${ }^{1}$, O. Ilizaliturri Guerra ${ }^{1}$, A. Cárdenas ${ }^{1}$, D. Á. Galarza-Delgado ${ }^{1}$, J. C. López Zamarrón ${ }^{1} .{ }^{1}$ Hospital Universitario Dr. José Eleuterio González, Rheumatology, Monterrey, Mexico

Background: Sexual dysfunction is defined as a change in any component of sexual activity, which may cause frustration, pain and decreased sexual intercourse ${ }^{1}$. Rheumatoid arthritis (RA) is a systemic autoimmune disease, which may lead to decline in joint mobility, pain, and fatigue; these impairments may influence the sexual health of patients ${ }^{2}$.

Objectives: The main aim of this study is to determine if there is an altered sexual function in Mexican women with RA and compare if it occurs in a greater proportion than in healthy women.

Methods: A case-control study that included Mexican women between 18 and 65 years, with RA diagnosis (according to ACR/EULAR 2010 criteria) and age-matched controls was performed. Patients were excluded if they couldn't answer the questionnaires reliably or were currently pregnant. They were asked about their sexual activity in the last month, and the Arizona Sexual Experiences Scale (ASEX), Hospital Anxiety and Depression Scale (HADS) and Functional Assessment of Chronic Illness Therapy (FACIT) self-questionnaires were applied; disease activity was assessed by DAS-28. Variables were compared between groups with student $\mathrm{T}$ test for independent samples and chi-square.

Results: We included 102 RA patients and 101 controls. Baseline demographic characteristics between groups are shown in Table 1. Women with RA had less sexual activity than controls (48.03\% vs. $90.09 \%, p<0.001)$. Out of the total women included, the ASEX was applied only to those that had an active sex life, 49 with RA and 91 controls. Sexual dysfunction (> 18 points) was found in $55.1 \%$ of women with RA and in $52.74 \%$ of controls, with no significant differences $(p=0.860)$; the prevalence of severe fatigue was higher in RA than in the healthy group $(p=0.009)$ (Table 2$)$. Women with RA and sexual dysfunction had higher levels of anxiety $(p=0.024)$ and fatigue $(p=$ 0.008 ) than those with RA without sexual dysfunction; however, no significant difference was found in age, depression and level of disease activity between these groups.

Table 1. Comparison of demographic variables between groups.

\begin{tabular}{lccc}
\hline & $\begin{array}{c}\text { RA GROUP } \\
(\mathrm{n}=102)\end{array}$ & $\begin{array}{c}\text { CONTROL GROUP } \\
(\mathrm{n}=101)\end{array}$ & $\mathrm{P}^{*}$ \\
\hline Age, years $( \pm \mathrm{SD})$ & $52.98(+/-13.36)$ & $52.45(+/-8.34)$ & 0.738 \\
Sexual activity in the last month, $\mathrm{n}(\%)$ & $49(48.03 \%)$ & $91(90.09 \%)$ & $<0.001$ \\
Civil status & & & 0.456 \\
Single, $\mathrm{n}(\%)$ & $26(25.5 \%)$ & $18(17.82 \%)$ & \\
Married, $\mathrm{n}(\%)$ & $43(42.2 \%)$ & $55(54.45 \%)$ & \\
Divorced, $\mathrm{n}(\%)$ & $15(14.7 \%)$ & $11(10.89 \%)$ & \\
Domestic partnership, $\mathrm{n}(\%)$ & $5(4.9 \%)$ & $4(3.96 \%)$ & \\
Widowed, $\mathrm{n}(\%)$ & $13(12.7 \%)$ & $13(12.87 \%)$ & \\
Menopause, $\mathrm{n}(\%)$ & $70(68.6 \%)$ & $72(71.28 \%)$ & 0.760 \\
Has children, $\mathrm{n}(\%)$ & $88(86.3 \%)$ & $83(82.17 \%)$ & 0.447 \\
\hline
\end{tabular}

T de student or Chi-Square test according to type of variable
Table 2. Difference in means of survey scores and frequencies of abnormal scores between groups.

\begin{tabular}{lccc}
\hline & $\begin{array}{c}\text { RA GROUP } \\
(\mathrm{n}=49)\end{array}$ & $\begin{array}{c}\text { CONTROL GROUP } \\
(\mathrm{n}=91)\end{array}$ & $\mathrm{P}^{*}$ \\
\hline ASEX score $( \pm \mathrm{SD})$ & $15.65+/-4.82$ & $15.45+/-5.07$ & 0.819 \\
Sexual dysfunction, $\mathrm{n}(\%)$ & $27(55.1 \%)$ & $48(52.74 \%)$ & 0.860 \\
HADS-A, anxiety subscale $( \pm \mathrm{SD})$ & $6.53+/-3.95$ & $7.15+/-3.98$ & 0.378 \\
HADS- D, depression subscale $( \pm \mathrm{SD})$ & $5.34+/-4.12$ & $4.32+/-3.20$ & 0.108 \\
Fatigue score (FACIT) $( \pm \mathrm{SD})$ & $34.42+/-9.52$ & $39.21+/-8.37$ & $0.003^{*}$ \\
Severe fatigue symptoms, $\mathrm{n}(\%)$ & $17(34.69 \%)$ & $13(14.28 \%)$ & $0.009^{*}$
\end{tabular}

$\mathrm{T}$ de student or Chi-Square test according to type of variable

* Statistically significant difference.

High scores HADS, ASEX and low scores in FACIT indicate severity.

Conclusion: In this study, women with RA have less sexual activity than healthy women, but no greater sexual dysfunction. Patients with RA and sexual dysfunction have more anxiety and fatigue; but they have no difference in age, disease activity and depression than those with RA and normal sexual function.

References:

[1] Henrique P, Queiroz T, Almeida D, et al. Como o reumatologista pode orientar o paciente com artrite reumatoide sobre func, ão sexual. Rev Bras Reumatol. 2014;55(5):458-463.

[2] Zhao S, Li E, Wang J, Luo L, Luo J, Zhao Z. Rheumatoid Arthritis and Risk of Sexual Dysfunction: A Systematic Review and Metaanalysis. 2018;45(10).

Disclosure of Interests: None declared

DOI: 10.1136/annrheumdis-2020-eular.4035

\section{\begin{tabular}{|l|l}
\hline AB0264 ARTERIAL STIFFNESS IN RHEUMATOID ARTHRITIS \\
\hline
\end{tabular} PATIENTS AS A POTENTIAL PREDICTOR OF EARLY CARDIOVASCULAR AGEING AND} MORBIDITY

M. Schubertová ${ }^{1}$, A. Smržová ${ }^{1}$, P. Horak ${ }^{1}$, M. Skácelová ${ }^{1}$, E. Lokočová ${ }^{1}$,

Z. Heřmanová ${ }^{2}$, F. Mrázek ${ }^{2}{ }^{1}$ Palacky University Olomouc, University Hospital Olomouc, Department of Internal Medicine III - Nephrology, Rheumatology and Endocrinology, Olomouc, Czech Republic; ${ }^{2}$ Palacky University Olomouc, University Hospital Olomouc, Department of immunology, Olomouc, Czech Republic

Background: Cardiovascular disease (CVD) is one of the most common causes of death in Rheumatoid arthritis patients. Increased arterial stiffness is considered as an independent risk factor of development CVD and a predictor of all-cause morbidity and mortality. Increased arterial stiffness, due to premature vascular ageing, can be observed in patients with chronic inflammatory diseases as well as in RA patients.

Objectives: To evaluate arterial stiffness determined as carotid - femoral pulse wave velocity in rheumatoid arthritis patients. The comparison of traditional and nontraditional risk factor of CVD, disease activity and laboratory findings connected with subclinical atherosclerotic changes.

Methods: We evaluated data of 50 patients with rheumatoid arthritis (39 females, 11 male, mean age 57 , mean duration of disease of $13 y e a r s)$. The arterial stiffness, measured as carotid - femoral pulse wave velocity (PWV), was established with the SphygmoCor system. This non-invasive technique uses the principle of applanation tonometry. Our control group counted 25 heathy male and females with no history of CVD or autoimmune disease. We evaluated the influence of traditional risk factors for CVD as age, smoking, BMI, lipid profile, diabetes mellitus, history of $\mathrm{CV}$ and cerebrovascular morbidity to PWV in RA patients. Non-traditional risk factors contained Adiponectin, Fetuin A, Endothelin-1 and Asymmetric dimethylarginine. To measure disease activity was used DAS 28 and inflammatory parameters as a marker of current disease activity. For chronic changes was used X-ray of small joints. Results were correlated with PWV and statistically evaluated.

Results: Mean PWV in Rheumatoid arthritis patients was significantly higher $(9.7 \mathrm{~m} / \mathrm{s})$ than that in healthy control group $(6.7 \mathrm{~m} / \mathrm{s}) .49 \%$ of RA patients $(\mathrm{n}=$ 24 ) had increased arterial stiffness according to their age. $32 \%$ patients $(n=16)$ with PWV over $10 \mathrm{~m} / \mathrm{s}$ that indicates aortal function alteration. We didn't find correlation between arterial stiffness and traditional and non-traditional CVD risk factors. Increased PWV was not associated with high disease activity. Patients with higher arterial stiffness according to their age had longer RA history, higher level of rheumatoid factor, were more frequently anti-citrullinated protein antibodies (ACPA) negative and were more frequently treated with biological therapy. 